\title{
Erratum to: Jesus the Healer: A Sermon in Honor of the Memory of Donald Eric Capps (1939-2015)
}

\author{
Donald R. Ferrell ${ }^{1}$
}

Published online: 27 July 2016

(C) Springer Science+Business Media New York 2016

\section{Erratum to: J Relig Health DOI 10.1007/s10943-015-0164-9}

The original article contains some errors.

- The article title omitted a comma. The beginning of the title should read: Jesus, the Healer:

- In page 2, line 15 of the article, the text, "Tell that congregant that you do have a psychiatrist. His name is Jesus of Nazareth!" should read "Remind the congregation that you do have a psychiatrist. His name is Jesus of Nazareth!"

- In page 2, line 23, a comma was omitted. The text should read: Jesus, the Healer:

- In page 3, line 2, the name should read: Max von Sydow

- In page 3, line 8 , the location should read: Treblinka

- In page 3, line 39, two commas were omitted. The text should read: It is Jesus, the healer, that

- In page 6 , line 33 , the text "whatever our afflictions, physical or emotional" should read: "whatever one's afflictions, physical and psychological".

The online version of the original article can be found under doi:10.1007/s10943-015-0164-9.

Donald R. Ferrell

ferrelld@earthlink.net

1 C. G. Jung Institute of New York, 46 Grouse Lane, Dorset, VT 05251, USA 